\title{
Article
}

\section{HADES: A Multi-Agent Platform to Reduce Congestion Anchoring Based on Temporal Coordination of Vessel Arrivals-Application to the Multi-Client Liquid Bulk Terminal in the Port of Cartagena (Spain)}

\author{
Pilar Jiménez ${ }^{1, *(\mathbb{D}}$, José María Gómez-Fuster ${ }^{2}$ a and Pablo Pavón-Mariño ${ }^{3,4}$ \\ 1 Department of Mining and Civil Engineering, Technical University of Cartagena, 30203 Cartagena, Spain \\ 2 Port Authority of Cartagena, Plaza Héroes de Cavite, 30201 Cartagena, Spain; jmgomez@apc.es \\ 3 Telecommunication Networks Engineering Group (GIRTEL), Department of Communications and \\ Information Technologies, Technical University of Cartagena, 30202 Cartagena, Spain; pablo.pavon@upct.es \\ 4 E-lighthouse Network Solutions, 30203 Cartagena, Spain \\ * Correspondence: pilar.jimenez@upct.es
}

Citation: Jiménez, P.; Gómez-Fuster, J.M.; Pavón-Mariño, P. HADES: A Multi-Agent Platform to Reduce Congestion Anchoring Based on Temporal Coordination of Vessel Arrivals-Application to the

Multi-Client Liquid Bulk Terminal in the Port of Cartagena (Spain). Appl. Sci. 2021, 11, 3109. https://doi.org/ 10.3390/app11073109

Academic Editor:

Emanuele Carpanzano

Received: 5 March 2021

Accepted: 29 March 2021

Published: 31 March 2021

Publisher's Note: MDPI stays neutral with regard to jurisdictional claims in published maps and institutional affiliations.

Copyright: (c) 2021 by the authors. Licensee MDPI, Basel, Switzerland. This article is an open access article distributed under the terms and conditions of the Creative Commons Attribution (CC BY) license (https:// creativecommons.org/licenses/by/ $4.0 /)$.
Featured Application: HADES, a software tool for the optimal operation of liquid bulk terminal management, is based on an optimization model for the allocation of liquid bulk berths to reduce congestion and vessel waiting time. By means of a user-friendly interface, all the agents involved in the process share the data relevant to optimal quay management, supervised by port authorities.

Abstract: Ports are key factors in international trade, and new port terminals are quite costly and time consuming to build. Therefore, it is necessary to optimize existing infrastructure to achieve sustainability in logistics. This problem is more complex in multi-client port terminals, where quay infrastructure is shared among terminal operators who often have conflicting interests. Moreover, the berth allocation problem in liquid bulk terminals implies demanding restrictions due to the reduced flexibility in berth allocation for these types of goods. In this context, this paper presents HADES, a multi-agent platform, and the experience of its pilot use in the Port of Cartagena. HADES is a software platform where agents involved in vessel arrivals share meaningful but limited information. This is done to alleviate potential congestion in multi-client liquid bulk terminals, promoting a consensus where overall congestion anchoring is reduced. A study is presented using a mixed integer linear program (MILP) optimization model to analyze the maximum theoretical reduction in congestion anchoring, depending on the flexibility of vessel arrival time changes. Results show that $6 \mathrm{~h}$ of flexibility is enough to reduce congestion anchoring by half, and $24 \mathrm{~h}$ reduces it to negligible values. This confirms the utility of HADES, which is also briefly described.

Keywords: multi-agent platform; multi-client terminal; port management; congestion anchoring; liquid bulk terminal; berth allocation problem

\section{Introduction}

Maritime traffic is the main type of transport for goods, accounting for over 11 billion tons in 2018 [1], and it is directly related to a country's economic activity: higher volumes of traffic yield greater activity and vice versa. In this context, port congestion implies a loss of time and money for all the actors in the logistic chain and therefore undermines the competitive position of ports and the ecosystem of companies in port communities [2].

Port infrastructure is costly and time consuming, and currently, bearing sustainability in mind, construction of new port terminals is probably not the best solution. It is important to keep in mind that in liquid bulk terminals, especially when managing IMDG products (international maritime dangerous goods), berth allocation is highly constrained, typically 
not because of the berthing infrastructure but because the loading arm, which is highly specific with respect to the good to load/unload (e.g., phenol, methanol, gasoline, jet fuel, LNG) have particular chemical characteristics or temperature requirements. This limited flexibility in allocation results in the appearance of congestion limitations when they reach around $30-40 \%$ occupancy.

From the perspective of port management, optimizing quay operations to reduce congestion and delays in the loading and unloading of vessels is addressed by the socalled berth allocation problem (BAP). The objective of berth allocation is to serve a set of vessels on a set of piers for a given period in order to optimize parameters like total vessel operation time, fuel consumption, and emissions. The improvement of berth usage reduces not only the port costs of loading and unloading vessels but their downtime costs. Thus, economic growth for ports and their activity, client loyalty, and attracting new clients are expected, all of which indirectly influence society.

The study of the berth allocation problem has been extensively developed for container terminals. However, liquid bulk terminals have received little attention in recent years, mainly due to the uncertainties and more demanding restrictions in the operation of these types of goods. In liquid bulk terminals, the berth where a vessel must stay is often determined by the goods to be loaded or unloaded since specific pipes and facilities are required. For this reason, there are few or no possibilities of changing operations from congested quays to other, less congested terminals or quays, which is a common approach to reducing congestion in container-based operations.

From a commercial point of view, there are a few software tools to manage liquid bulk berths. The existing ones are all costly and have been developed for container terminals, sometimes even for specific terminals, such as Posidonia Operation [3], Dropboard [4], and Marine Enterprise Suite [5]. In addition, all these tools share opacity in terms of the optimization or heuristic models used for berth assignment, and they allow for little improvement from the user interface.

Furthermore, maritime logistic chains involve many agents and companies with different interests. In multi-client port terminals, the quay infrastructure is shared among terminal operators with conflicting interests, although all clients have the common goal of reducing the anchoring time caused by vessel congestion and increasing operational capacity.

In liquid bulk terminals, vessel arrival times can frequently be macroscopically determined by terminal owners or petrochemical companies far in advance due to the terms of trading contracts. Thus, fostering temporal coordination among terminal operators to produce schedules that avoid simultaneous vessel arrivals at the same terminal can be a solution to congestion anchoring. Currently, company/terminal operators work individually using their own equipment, and there is no communication among them, even though they share the same resources offered by the port authority.

This paper presents the multi-agent platform HADES, developed in collaboration with the Cartagena Port Authority, in Spain. HADES has two objectives: (i) to foster coordination among the different port agents and terminals and (ii) to solve the BAP problem in multiclient liquid bulk terminals. HADES adds to the literature about BAP problems by focusing on multi-client liquid bulk terminals, making coordination among the different port agents easier to achieve and providing improvements to the value chain associated with trade, which results in more efficient, sustainable, and competitive logistic chains.

Specifically, HADES is a software tool for the optimal operation of liquid bulk terminal management developed by E-lighthouse. This tool is based on an optimization model for the allocation of liquid bulk berths to reduce congestion and vessel waiting time. Based on information technologies, HADES facilitates coordination among the different port agents. It allows the three main agents of the logistic-port community: terminal operators/owners, shipping agents, and port authorities to communicate. By means of a user-friendly interface, all the agents involved in the process share the data relevant to optimal quay management, supervised by port authorities. 
This project has been promoted by the Cartagena Port Authority. Since 2016, an increase in delays at numerous liquid bulk berths (for petroleum, petroleum products, oil, and chemical products, among others) in the Escombreras Basin has been detected. These delays have increased the number of vessels having to anchor as well as their anchoring time due to congestion. In fact, an analysis of the multi-client E010 dock, with data from January 2010 to August 2020, estimates that anchoring congestion was the reason for an annual average anchoring time of $6.3 \mathrm{~h}$ per call (over an average call time of $45.28 \mathrm{~h}$ ), with an estimated cost of 500,000 EUR per year in ship freight.

The document is organized as follows. In Section 2 a literature review of temporal coordination procedures and BAP models is described. Section 3 presents the HADES tool. Section 4 provides the algorithm applied to solve the berth allocation problem, considering the restrictions related to liquid bulk. The real application to the liquid bulk terminal in the Port of Cartagena (Spain) is shown in Section 5. Finally, in Section 6, conclusions are drawn, together with a discussion about the future research lines of HADES.

\section{Literature Review}

\subsection{Temporal Coordination Procedures}

Maritime logistic chains involve many agents and companies with different types of organizations. In multi-client port terminals, understood as terminals where the quay infrastructure is shared by several terminal operators that have placed loading arms in the same quay infrastructure, conflicting interests appear. Each terminal operator seeks a profit and a return on their investment, although all of them have common interests, such as reducing the anchoring time of their vessels caused by congestion and increasing their operational capacity. Port authorities pursue both private and public goals like contributing to regional economic growth and enhancing sustainability.

The effects and implications of cooperation among all the different port agents in container terminals have been studied extensively in recent years. Specifically, the Port of Rotterdam and the Port of Barcelona have been analyzed to understand how the quality of hinterland access (trucks, railways, and barges) is important for seaport competitiveness [6-11].

Van der Horst and de Langen [7] identified a set of coordination problems among the actors involved in a port's hinterland chain and propose different coordination arrangements. The four coordination mechanisms are the introduction of incentives, the creation of an interfirm alliance, changing scope, and creating collective action. Incentives influence the behavior of actors. For example, bonuses or penalties could be established for companies that follow (or do not follow) the operational rules of a terminal operator. Interfirm alliances imply more responsibility and common arrangements among companies than incentives. They can include subcontracting, standards for quality and services, or formalized procedures. Possible coordination measures to change the scope of an organization could be vertical integration or the introduction of a new market. The last category enhances collective instead of individual action; for instance, branch associations or the development of information technology systems for a sector of the port industry or its whole.

The multi-agent platform described in the manuscript is based on the last category because it seeks collective action for operational improvement in liquid bulk terminals.

From a commercial standpoint, there are a few software tools to coordinate different port agents and manage liquid bulk berths. The existing ones (see Table 1) are costly, have been developed for container terminals, and are mostly designed for specific terminals. All these tools share opacity in terms of the optimization or heuristic models used for berth assignment and allow for little improvement from the user interface.

Table 1 summarizes the current products available for port operations. Most of them can be applied to liquid bulk terminals, except PortChain-Motor optimization [12]. It focuses only on container terminals. Shipping companies are the main users of port operation software, although the relationships with terminal operators and port authorities are also considered in some software products (Suite Posidonia-ProdevelopSpain [3], PortChain-Motor optimization—Denmark [12], Marine Enterprise Suite- 
Cirrus Logistics-United Kingdom [5]). The proposed multi-agent platform HADES considers the coordination among shipping companies, terminal operators, and port authorities in terminals dedicated to liquid bulk. Therefore, HADES provides a new perspective to the temporal coordination problem in liquid bulk terminals, considering the different port agents involved.

Table 1. Commercial products for port operations.

\begin{tabular}{|c|c|c|c|c|}
\hline Product & Description & $\begin{array}{l}\text { Applicable to Liquid } \\
\text { Bulk Terminals }\end{array}$ & Users & $\begin{array}{c}\text { Cooperative } \\
\text { Tool }\end{array}$ \\
\hline $\begin{array}{c}\text { Port Authority of Valencia-Spain } \\
\text { [13] }\end{array}$ & $\begin{array}{l}\text { Information analysis to detect } \\
\text { inefficiencies in port operations }\end{array}$ & Yes & Shipping companies & No \\
\hline $\begin{array}{c}\text { Suite } \\
\text { Posidonia-Prodevelop_Spain [3] }\end{array}$ & $\begin{array}{l}\text { System to centralize information, with } \\
\text { modules specialized in processes } \\
\text { (general management of the port, } \\
\text { management of its operations, } \\
\text { management of terminals) }\end{array}$ & Yes & $\begin{array}{l}\text { Shipping companies, } \\
\text { terminal operators, } \\
\text { port authorities }\end{array}$ & No \\
\hline PortXchange-Rotterdam [14] & $\begin{array}{l}\text { The platform combines public, } \\
\text { third-party data and AI forecasts to } \\
\text { generate accurate information for the } \\
\text { shipping company on the planning of } \\
\text { a call }\end{array}$ & Yes & Shipping companies & No \\
\hline QronoPort-Antwerp [15] & $\begin{array}{l}\text { Collaborative platform to reduce waiting } \\
\text { times with data-assisted planning and } \\
\text { predictive models }\end{array}$ & Yes & Terminal operators & No \\
\hline Navi-Port_-Wartsila Finland [16] & $\begin{array}{l}\text { Middleware of dynamic exchange of } \\
\text { information between ship and port for } \\
\text { "Just In Time Arrival" }\end{array}$ & Yes & Shipping companies & No \\
\hline $\begin{array}{l}\text { PortChain-Motor } \\
\text { optimization-Denmark [12] }\end{array}$ & $\begin{array}{c}\text { AI-based planning tool to maximize } \\
\text { terminal and carrier utilization } \\
\text { and capacity }\end{array}$ & No & $\begin{array}{l}\text { Shipping companies } \\
\text { and terminal } \\
\text { operators }\end{array}$ & No \\
\hline $\begin{array}{c}\text { Dropboard-Systems } \\
\text { Navigator-Netherlands [4] }\end{array}$ & $\begin{array}{l}\text { Tool for planning and scheduling } \\
\text { resources using data-based algorithms }\end{array}$ & Yes & Terminal operators & No \\
\hline $\begin{array}{c}\text { Marine Enterprise Suite-Cirrus } \\
\text { Logistics-UK [5] }\end{array}$ & Operational planning tool & Yes & $\begin{array}{l}\text { Shipping companies, } \\
\text { terminal operators, } \\
\text { port authorities }\end{array}$ & No \\
\hline $\begin{array}{l}\text { Hades-Port Authority of } \\
\text { Cartagena-Spain }\end{array}$ & $\begin{array}{l}\text { Platform that aggregates historical, } \\
\text { current, and future data on an } \\
\text { application execution environment to } \\
\text { improve port planning }\end{array}$ & Yes & $\begin{array}{l}\text { Shipping companies, } \\
\text { terminal operators, } \\
\text { port authorities }\end{array}$ & Yes \\
\hline
\end{tabular}

\subsection{The Berth Allocation Problem (BAP)}

From the point of view of port management, one of the problems to address is to reduce congestion and delays in vessel loading and unloading as much as possible. This is the Berth Allocation Problem (BAP). The objective of berth allocation is to service a set of vessels on a set of piers for a given period. The objectives addressed more frequently in the literature are (i) minimizing total vessel operating and waiting time; (ii) minimizing early or late departures with respect to scheduled times; and (iii) minimizing fuel consumption and emissions.

There are several spatial and temporal constraints involved in BAP problems, leading to a multitude of formulations. Time restrictions are related to the vessel arrival process, the start of the service, and vessel handling times. Spatial restrictions are based on the design of the docks and their use (shared or not).

According to Bierwirth and Meisel [17], a vessel's arrival process can be considered static or dynamic. In static arrivals, all ships are already in port. In dynamic arrivals, only a number of the scheduled ships are in port and the rest are assigned arrival times. These arrival times can be considered deterministic, with fixed values, or stochastic, in which a distribution of arrival times can be given to reflect the uncertainty of arrivals. 
Spatial restrictions limit the feasible docking positions of vessels according to a preestablished division of the quay into alignments. Based on berth design, the BAP can be classified as discrete, continuous, or hybrid [17]. In the discrete case, the dock is divided into a set of sections and only one ship can be serviced per section at any given time [18-20]. In the continuous case, there is no dock division and a ship can occupy any arbitrary position along the dock [21-23]. This leads to better utilization of dock space; however, it is computationally more complicated. In the hybrid case, the dock is divided into a set of sections but a vessel can occupy more than one section at a time, and several vessels are also allowed to share the same alignment at the same time [24,25].

The study of the berth allocation problem in liquid bulk terminals (liquid bulk-BAP) has received little attention in recent years, mainly due to the uncertainties and more demanding restrictions, such as specialized pipelines or conveyers, involved in these types of operations. Table 2 shows recent papers about liquid bulk-BAP problems. For each reference, the type of algorithms used, the purpose of their objective function, and the characteristics considered, based on vessel arrival times and spatial constraints, are indicated.

Some authors [26-28] proposed a mixed integer programming (MIP) model to minimize total vessel service time, considering a dynamic vessel arrival time and hybrid $[26,27]$ or discrete spatial constraints [28]. Moreover, [29] study and solve the problem of recovering a baseline vessel berthing schedule in a port in real time as disruptions occur. The uncertainty of vessel arrival and handling times is modeled on probability distributions derived from past data.

Various metaheuristic models are used to solve bulk-BAP problems. These algorithms allow several problems to be worked on together, such as bulk-BAP and yard assignment problems [27]. Other algorithms minimize waiting time, ship operating time after berthing, and ship priority deviation based on decision support systems [30,31].

Recently, machine learning techniques have been applied to minimize the cost associated with vessel handling operations [32].

In this case of study, the BAP is based on dynamic vessel arrivals since this arrival time is a variable decision and discrete from spatial restrictions. This is because liquid bulk quays only have one possible mooring position, determined by product handling systems. The BAP at this level aims to optimize the delays and waiting times for liquid bulk carriers and maximize the port's turnaround.

All the cited papers related to bulk-BAP are focused on the mathematical problem. However, this paper presents a platform where the mathematical model is integrated. The characteristic of being multi-agent, that is, the platform uses data not only provided by ships but also from terminal operators/owners and port authorities, is a distinctive feature.

Table 2. Related works about the berth allocation problem in bulk terminals.

\begin{tabular}{|c|c|c|c|c|c|}
\hline Ref. & Algorithm & Goal & & Vessel Arrival Time & $\begin{array}{l}\text { Spatial } \\
\text { Constraint }\end{array}$ \\
\hline \multirow{3}{*}[26]{} & $\begin{array}{c}\text { Mixed integer programming } \\
\text { (MIP) }\end{array}$ & $\begin{array}{c}\text { Minimize total service time of } \\
\text { vessels }\end{array}$ & Dynamic & Input data & Hybrid \\
\hline & Generalized set partitioning & $\begin{array}{c}\text { Minimize total service time of } \\
\text { vessels }\end{array}$ & Dynamic & $\begin{array}{c}\text { Input data as discrete time } \\
\text { intervals }\end{array}$ & Hybrid \\
\hline & $\begin{array}{c}\text { Metaheuristic: squeaky wheel } \\
\text { optimization (SWO) }\end{array}$ & $\begin{array}{c}\text { Minimize total service time of } \\
\text { vessels }\end{array}$ & Dynamic & Input data & Hybrid \\
\hline \multirow{3}{*}[27]{} & MIP & $\begin{array}{c}\text { Minimize total service time of } \\
\text { vessels }\end{array}$ & Dynamic & $\begin{array}{l}\text { Output: discrete time intervals } \\
\text { as decision variable }\end{array}$ & Hybrid \\
\hline & Heuristic: branch and price & $\begin{array}{c}\text { Minimize total service time of } \\
\text { vessels (including yard } \\
\text { assignment) }\end{array}$ & Dynamic & $\begin{array}{l}\text { Output: discrete time intervals } \\
\text { as decision variable }\end{array}$ & Hybrid \\
\hline & $\begin{array}{l}\text { Metaheuristic: critical-shaking } \\
\text { neighborhood search (CSNS) }\end{array}$ & $\begin{array}{c}\text { Minimize total service time of } \\
\text { vessels (including yard } \\
\text { assignment) }\end{array}$ & Dynamic & $\begin{array}{l}\text { Output: discrete time intervals } \\
\text { as decision variable }\end{array}$ & Hybrid \\
\hline$[30]$ & $\begin{array}{l}\text { Metaheuristic: nonsorting } \\
\text { genetic algorithm } \\
\text { (Mod-NSGA II) }\end{array}$ & $\begin{array}{l}\text { Minimize total waiting time of } \\
\text { vessels at anchorage and ship } \\
\text { priority deviation }\end{array}$ & Dynamic & Input data & Discrete \\
\hline
\end{tabular}


Table 2. Cont.

\begin{tabular}{|c|c|c|c|c|c|}
\hline Ref. & Algorithm & Goal & & Tessel Arrival Time & $\begin{array}{l}\text { Spatial } \\
\text { Constraint }\end{array}$ \\
\hline$[32]$ & Machine learning & $\begin{array}{l}\text { Minimize total service time of } \\
\text { vessels }\end{array}$ & Dynamic & Input data & Hybrid \\
\hline \multirow{2}{*}{ [31] } & $\begin{array}{l}\text { Metaheuristic: controlled elitist } \\
\text { nondominated sorting genetic } \\
\text { algorithm (CENSGA-II) }\end{array}$ & $\begin{array}{l}\text { Minimize total waiting time of } \\
\text { vessels at anchorage and } \\
\text { operating time and ship priority } \\
\text { deviation }\end{array}$ & Dynamic & Input data & Discrete \\
\hline & $\begin{array}{l}\text { Metaheuristic: chemical } \\
\text { reaction optimization (CRO) }\end{array}$ & $\begin{array}{l}\text { Minimize total waiting time of } \\
\text { vessels at anchorage and } \\
\text { operating time and ship priority } \\
\text { deviation }\end{array}$ & Dynamic & Input data & Discrete \\
\hline \multirow{2}{*}{ [29] } & MIP & $\begin{array}{l}\text { Minimize total realized cost of } \\
\text { modified berthing schedule due } \\
\text { to a disruption }\end{array}$ & Dynamic & $\begin{array}{l}\text { Input data as discrete time } \\
\text { intervals }\end{array}$ & Hybrid \\
\hline & Heuristic: greedy algorithm & $\begin{array}{l}\text { Minimize total realized cost of } \\
\text { modified berthing schedule due } \\
\text { to a disruption }\end{array}$ & Dynamic & $\begin{array}{l}\text { Input data as discrete time } \\
\text { intervals }\end{array}$ & Hybrid \\
\hline [28] & MIP & $\begin{array}{c}\text { Minimize total service time of } \\
\text { vessels }\end{array}$ & Dynamic & Input data & Discrete \\
\hline HADES & MILP & $\begin{array}{l}\text { Minimize total service time of } \\
\text { vessels }\end{array}$ & Dynamic & $\begin{array}{l}\text { Output: discrete time interval } \\
\text { as decision variable }\end{array}$ & Discrete \\
\hline
\end{tabular}

\section{The HADES Framework}

The HADES system is a proof of concept of a coordination system among terminal operators, shipping agents, and port authorities that optimizes berth occupancy with the aim of increasing port resource efficiency. HADES is based on an optimization model that (i) recommends the allocation of liquid bulk berths to arriving vessels and (ii) suggests beneficial time shifts to vessel arrival times within realizable time windows that, if voluntarily applied by the involved actors, would positively influence overall efficiency.

HADES was developed by E-lighthouse Network Solutions, a start-up at the Technical University of Cartagena focused on mathematical optimization in different industrial sectors. HADES has a web interface for its users (https://hades.apc.es (accessed on 30 March 2021). User name and password are required). This prototype has been in operation since July 2020 in the Port of Cartagena (Spain), specifically, at the E010 and E011 multiclient alignments, both allocated to liquid bulk goods.

In this section, the context, purpose, and general guidelines of the HADES system are provided.

\subsection{The Port of Cartagena}

The Port of Cartagena constitutes two separate and independent docks: the Cartagena basin and the Escombreras basin. The distance between the two basins is 1.5 miles by sea and $5 \mathrm{~km}$ by road (Figure 1).

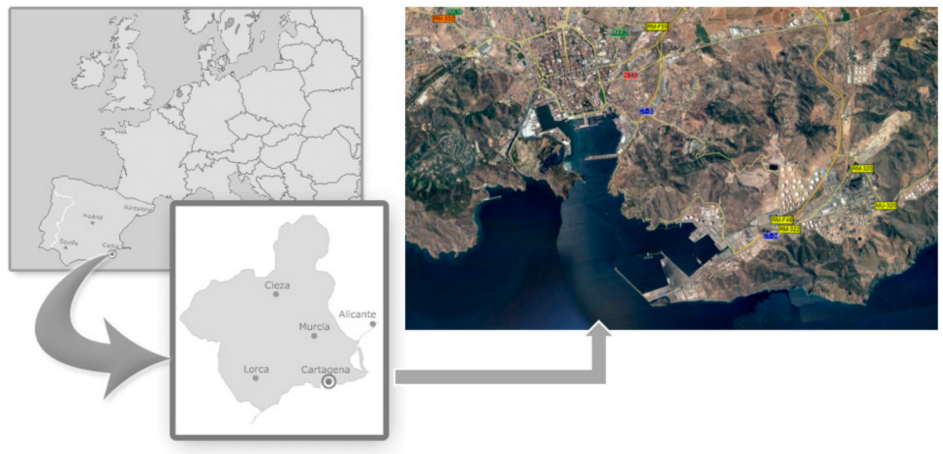

Figure 1. Port of Cartagena. Source: Google Earth. 
The liquid bulk terminal is in the Escombreras dock. It has 13 quays, of which 8 are single client; that is, they are only operated by one terminal operator, and 5 are multi-client, operated by more than one terminal operator-that is, the quay infrastructure is shared by several terminal operators that have placed loading arms in the same quay infrastructure (Figure 2).

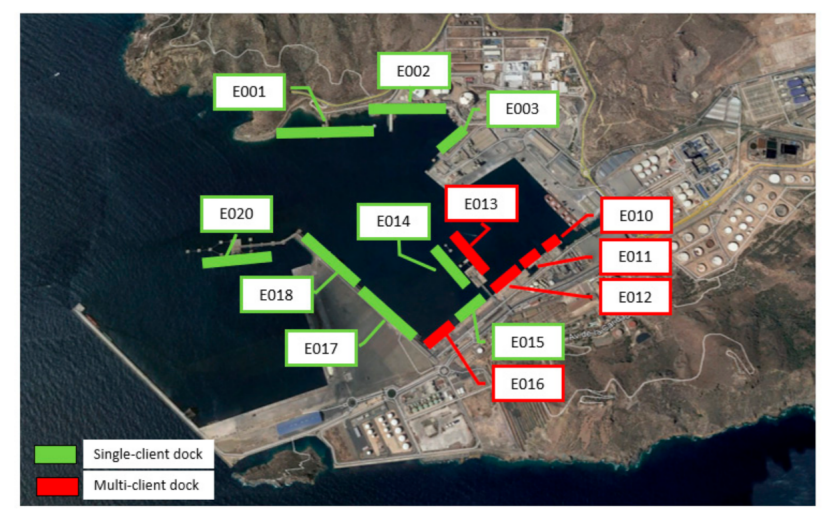

Figure 2. Liquid bulk terminal, Escombreras Dock, Port of Cartagena (Spain). Source of background: Google Earth.

The maritime traffic of liquid bulk is fundamental in this port. According to the data provided by the Cartagena Port Authority in $2019,75.8 \%$ of the tons moved in the port are liquid bulk, mainly crude oil and its byproducts [33] (see Figure 3). These figures put the Port of Cartagena in second place in liquid bulk traffic in Spain, only behind Algeciras, and ninth in the highest liquid bulk activity in Europe, according to statistics from the ESPO (European Sea Ports Organization, www.espo.be (accessed on 30 March 2021)).

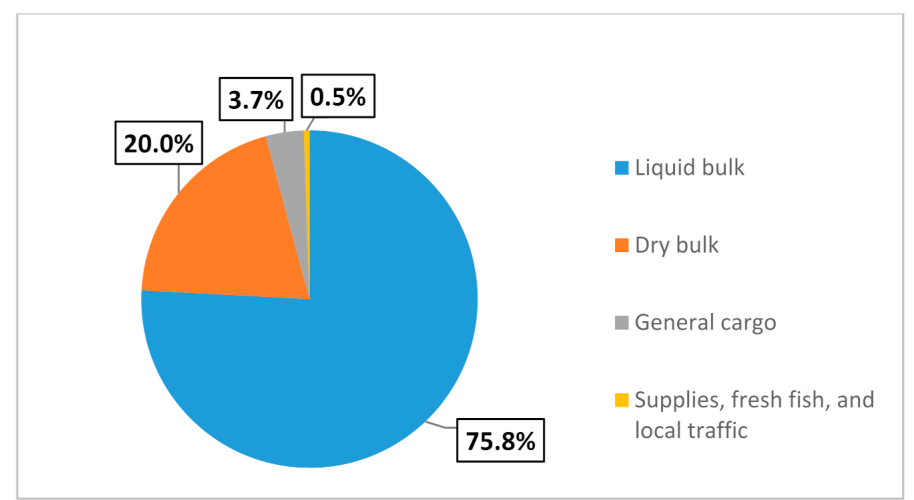

Figure 3. Maritime traffic of Port of Cartagena (Spain), 2019. Data source: [33].

\subsection{The Motives Driving the Development of HADES}

The division between the single- and multi-client liquid bulk docks and the importance of these goods in the port have driven the creation of HADES. Although congestion had been increasing since 2016, in 2019, efficiency problems in the use of some of its liquid bulk terminals were detected in the Port of Cartagena. A temporal occupation analysis and the practical experience of operation managers discovered unevenness in vessel arrivals, with weeks of high occupancy that produced anchoring delays for the vessels involved, followed by underutilized periods where resources were idle.

An internal analysis showed that there was little to no possibility of offloading vessels requesting operations in congested terminals to other terminals. That is, the large majority of the vessels arriving to the congested quays could not be served at any other quay due to the specific loading/unloading resources they needed. This was behind the idea of trying to influence the decision of arrival time by terminal users to smooth out the irregularity 
of vessel arrivals, stimulating a more uniform distribution of these arrivals, which would inherently result in fewer anchoring delays.

The process started with a number of meetings where relevant actors were formally queried about two aspects:

1. Their time margin flexibility. For a system like HADES to be workable, given that it recommends optimized shifts in vessel arrival times to terminal users, it is necessary to understand whether such time flexibility really exists among the Port of Cartagena users.

2. Their potential interest and acceptance of a system that provides such benefits, at the cost of sharing some of their vessel arrival information.

The answer was positive, with a one-day time margin flexibility informally announced and the explicit (and logical) constraint that this margin would be different for different operations. This feedback triggered the development of the HADES system.

\subsection{HADES Mission and Guidelines}

One of the objectives of HADES is to transform the berth programming methodology in multi-client terminals from linear to circular (Figure 4). In the current (linear) methodology, different agents communicate their arrival and berth planning to the port authority. That information is static and there is little opportunity to coordinate, leaving terminal operators with limited access to the information. As already mentioned, such uncoordinated arrivals often produce days of congestion (with vessels suffering delays) followed by days of underutilization with unoccupied fronts.

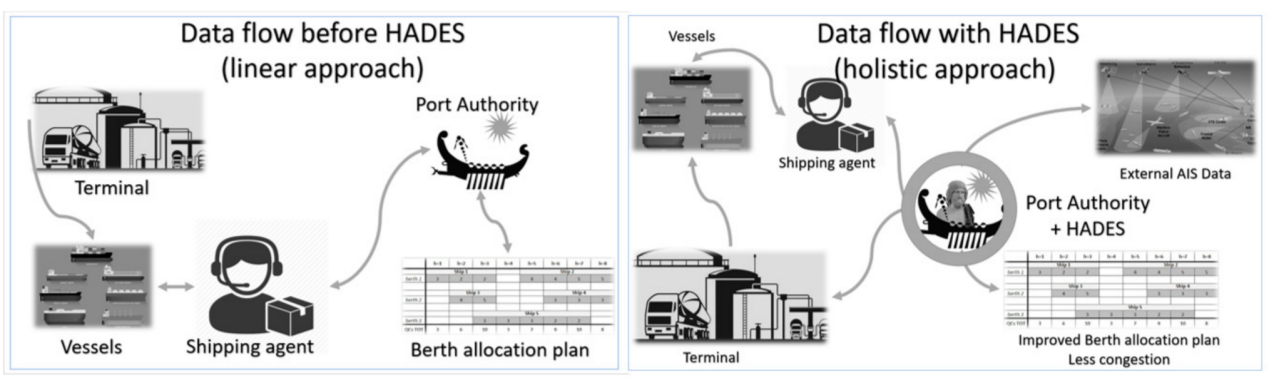

Figure 4. HADES transformation of berth planning programming methodology from linear to circular.

To address this situation, the mission of HADES is to promote, assist, and monitor time coordination at berths in multi-client terminals, which prevents congestion anchoring situations before they occur. Although applicable to any type of operation, it is estimated that this methodology will have special impact on liquid bulk terminals, whose operations cannot usually be diverted to other fronts. The result is a dynamic circular method, where users can adjust their arrivals in light of forecasts and estimated occupation.

The circular methodology of HADES encourages a more harmonious use of resources, promoting coordination among terminal operators, shipping agents, and port managers. HADES is conceived as a multi-agent platform, where the port authority is the owner, and the terminal operators share limited but relevant information.

HADES:

- Requires terminal operators to record expected future operations at target docks, including expected arrivals, required resources, and operation durations.

- Permits these operators and the port manager to visualize the forecasted quay occupation based on the previous information, and the operators to see if their projected operations would be simultaneous and, therefore, in conflict with operations recorded by other terminal operators. The aim is to promote consensual coordination in arrivals to reduce dead periods. 
- Periodically provides recommendations of vessel arrival time shifts to the terminal operators to reduce overall anchoring times, which may be accepted or not. Such recommendations are the output of the HADES time coordination algorithm, which jointly attempts to exploit the time flexibility in vessel arrivals and (if any) flexibility in quay allocation. The MILP optimization model prototype behind the joint allocation process is described in Section 4.

- Provides meaningful statistical information to the port authority on the efficient use of the port's resources and forecasted occupation to identify possible bottlenecks and improvements.

- Includes automatic methods to monitor the fair use of the system, identifying inefficient situations and bottlenecks. Monitoring and auditing fairness in accessing shared resources and automatically identifying misuse helps encourage proper behavior in multi-client systems. For instance, HADES is evolving to adopt a predictive system of vessel arrival times using automatic identification system (AIS) to verify the accuracy of the arrival estimates provided by users. To do so, it evaluates previous average accuracy in the operation durations estimated by HADES users.

HADES proof-of-concept, in operation in the Port of Cartagena since July 2020, is integrated into the port management system (PMS) of the Cartagena port in an application known as INTEGRA2 [34]. This application is used by most of the Spanish Port Authorities, which would facilitate the adoption of a similar system by other Spanish ports. INTEGRA2 includes a database that records multiple aspects of port operations, including a record of past vessel arrivals and resource use. HADES automatically reads from the INTEGRA2 system and includes an alternate database, which stores the estimated future vessel arrivals and resource occupation provided by port terminal users, and other information from the application business logic.

\section{Join Berth and Time Coordination Optimization Model}

This section describes the MILP at the heart of the HADES system prototype, which can jointly optimize (i) quay allocation decisions and (ii) limited variation in the arrival time of a vessel, with the intention of later recommending this variation to the terminal operator.

The optimization target considered in this description is to minimize average anchoring delays. However, it is important to note that, in practice, anchoring stays can exist for different reasons. One of these reasons could be to intentionally delay the loading or unloading of goods that have a fluctuating price (a typical situation with liquid bulk like petrol or gas) to increase profits. In contrast, this model is focused on reducing so-called congestion anchoring stays. This means, a nondesired anchoring stay that a vessel is forced to make since the berth/s that are appropriate for the vessel are occupied and the vessel must wait until the berth becomes available.

\subsection{Input Parameters}

Let $Q$ denote the set of quays under the control of this optimization model. Let $C$ denote the set of vessel calls in the port during the time in which we are going to perform the optimization. Each call $c \in C$ is characterized by the vessel $v(c)$ making the call and a sequence of so-called stays $S(c)$. A stay $s \in S(c)$ represents the anchoring of the vessel $v(c)$ in a particular quay $q(s)$ to perform a particular set of operations (e.g., loading/unloading of goods). Stays must be conducted in a particular order; the optimization model is not allowed to interchange them. We denote as $s_{\text {first }(c)}$ and $s_{\text {last }(c)}$ the first and last starts in the call $c$, respectively.

Each stay $s$ has a set of eligible quays where the involved operations should occur. This set is denoted as $Q(s)$. Typically, in liquid bulk operations, the $Q(s)$ sets are composed of a small number of options involving expensive and specific resources that are requested for the loading/unloading operations and are not replicated in multiple quays. The estimated duration of the operations associated with stay $s$, if performed in quay $q$, is denoted as 
$d(s, q)$. Note that this time may be different among the different eligible quays, e.g., when the loading of liquid goods is made via pipes, and pipes with different throughputs exist in different quays.

For each call $c \in C, t_{\min (c)}$ and $t_{\max (c)}$ denote the earliest and latest vessel arrival times to the port in the call. This defines the time flexibility window that the model has to optimize vessel arrival time. Additionally, there are pre-stay time constraints if there are some specific limitations, like a particular operation to be initiated not later than a given time. To accommodate this, $t_{\min (s)}$ and $t_{\max (s)}$ indicate the earliest and latest starting times of stay $s$. Note that a stay $s \in S(c)$ with the earliest starting time $t_{\min (s)}$ is always posterior to the call earliest starting time $\left(t_{\min (c)}\right)$ plus the duration of the previous stays in the same call, if any.

Finally, $P$ is the set of potential allocation conflicts that can exist between two particular stays of different calls $(s 1 \in S(c 1), s 2 \in S(c 2))$ at a particular quay $q$. Note that for a potential conflict to exist: 1) the two stays must have q among their eligible quays; and 2) the two time intervals $\left[t_{\min (s 1)}, t_{\max (s 1)}+t(s 1, q)\right]$ and $\left[t_{\min (s 2)}, t_{\max (s 2)}+t(s 2, q)\right]$ should be overlapping. These intervals are the earliest and latest time in which the quay can be occupied for each stay. If they do not overlap, no time decision can cause these two stays to have a conflict at that quay. Note that the set $P$, with all of the potential conflicts $(s 1, s 2, q)$, can be computed in advance from the input data.

\subsection{Decision Variables}

The decision variables of the problem follow:

- $\quad a(c)$, for all $c \in C$-arrival time to the port of the vessel $v(c)$, for its call $c \in C$. This call is constrained to fall within the interval $\left[t_{\min (c)}, t_{\max (c)}\right]$ that defines the flexibility available to change it.

- $\quad y(q, s)$, for all $c$, for all $s \in S(c)$, for all $q \in Q(s)$ - takes the value of one if quay $q$ is assigned for the berthing in stay $s$, belonging to call $c$ and 0 otherwise.

- $\quad a(s)$, for all $c$, for all s in $S(c)$ - the starting time of the occupation of the quay assigned for the berthing in stay $s$, belonging to call $c$.

- $o(p) \in\{0,1\}$, for all $p \in P$-in each potential conflict $(s 1, s 2, q)$, takes the value of one if both $s 1, s 2$ are assigned quay $q$, and thus a conflict is really possible and time overlapping is forbidden and 0 otherwise.

- $\quad x 1(p) \in\{0,1\}$, for all $p \in P$-for each potential conflict $(s 1, s 2, q)$, if $s 1$ and $s 2$ are assigned the conflicting quay $q$, this decision variable takes the value of 1 and $s 1$ is scheduled to occur before $s 2$ and 0 otherwise. If not, its value is undetermined and unimportant.

- $x 2(p) \in\{0,1\}$, for all $p \in P$-for each potential conflict $(s 1, s 2, q)$, if $s 1$ and $s 2$ are assigned the conflicting quay $q$, this decision variable takes the value of 1 and $s 2$ is scheduled to occur before $s 1$ and 0 otherwise. If not, its value is undetermined and unimportant.

\subsection{Objective Function}

The objective function (1) seeks to minimize the duration of calls; that is, the time between a vessel's arrival time to port (call start, $a(c))$ and the start time of the last stay of the call $\left(a\left(s_{\text {last }(c))) \text {. }}\right.\right.$

$$
\sum_{s}\left(a\left(s_{\text {last }}(c)\right)-a(c)\right)
$$

\subsection{Constraints}

Below, the problem constraints are enumerated together with their descriptions.

$$
a\left(\operatorname{first}_{s(c)}\right) \geq a(c) ; \forall c, \forall s \in S(c)
$$

Constraint (2) reflects that the first stay of the call cannot start before the arrival of the ship to the port.

$$
a(s) \geq a(\operatorname{prev}(s))+d(\operatorname{prev}(s)), \forall c \in C, \forall s \in S(c) \text { different to the first stay }
$$


Constraint (3) states that the order of the stays in a call has to be respected so that the starting of a stay cannot be before the operations of the previous one end. In fact, prev(s) denotes the previous stay in the same call.

$$
\sum_{s \in Q(s)} y(q, s)=1 ; \forall c \in C, s \in S(c)
$$

Constraint (4) indicates that each stay is assigned one and only one quay, among those eligible.

$$
\begin{gathered}
M(x 1(p)+o(p)-2) \leq a(s 2)-(a(s 1)+d(s 1, q)) \leq M(x 1(p)+1-o(p))), \forall p \in P \\
M(x 2(p)+o(p)-2) \leq a(s 1)-(a(s 2)+d(s 2, q)) \leq M(x 2(p)+1-o(p))), \forall p \in P \\
X 1(p)+x 2(p)=1, \forall p \in P
\end{gathered}
$$

Constraint (5) sets the value of $x 1$ for each potential conflict $p=(s 1, s 2, p)$ when both $s 1$ and $s 2$ are assigned the same quay $q$ (and thus $o(q)=1$ ): if $s 1$ is before and $s 2$ and does not overlap it (and thus $t(s 2)-(t(s 1+d(s 1, q))) \geq 0$ ), then $x 1$ is forced to have the value of one and is forced to take the value of 0 otherwise. For this to happen, parameter $M$ should be a sufficiently large constant, greater than any difference between time events in the system. Constraint (6) repeats the same behavior for the case of $x 2$, setting its value to 1 if and only if $s 2$ occurs before $s 1$ and does not overlap it timewise. Constraint (7) means that $s 1$ is earlier and does not overlap $s 2$, or else $s 2$ is earlier and does not overlap $s 1$, but one of the two options must occur.

Assuming that $s 1$ and $s 2$ are not assigned the same quay, the variable $o(p)=0$ and Constraint (6) and Constraint (7) do not restrict the values of $x 1$ and $x 2$, which are free to take values of 0 or 1 . Then, the variables would take either the value of $x 1(p)=0, x 2(p)=1$, or the opposite, to satisfy (7).

$$
\begin{gathered}
O(p) \leq y(q, s 1), \forall p=(q, s 1, s 2) \in P \\
O(p) \leq y(q, s 2), \forall p=(q, s 1, s 2) \in P \\
O(p) \leq y(q, s 1)+y(q, s 2)-1, \forall p=(q, s 1, s 2) \in P
\end{gathered}
$$

Constraints (8)-(10) make $o(p)$ take the value of 1 when both $s 1$ and $s 2$ in the conflict are assigned quay $q(y(q, s 1)=1, y(q, s 2)=1)$ and 0 otherwise.

\subsection{Time Normalization}

To avoid numerical problems during the optimization solver execution, all the time variables $t(c)$ and $t(s)$ are converted into so-called normalized times when introducing their values into the solver. In particular, $D_{1}$ indicates the initial date of the earliest call in the dataset to use in the optimization and $D_{2}$ the ending date of the last stay among all the calls in the dataset. Then, each date $d$ is converted into normalized time $t$ as follows:

$$
t=100\left(d-D_{1}\right) /\left(D_{2}-D_{1}\right)
$$

By doing so, each date that is an input parameter to the problem $(a(c) ; a(s))$ is converted into a number between 0 and 100, and durations are also normalized accordingly. After the optimization is run, the obtained $a(s)$ and $a(c)$ values, which are normalized dates, are converted into regular dates by reversing Equation (11):

$$
d=D_{1}+t\left(D_{2}-D_{1}\right) / 100
$$




\section{Application to the Liquid Bulk Terminal in the Port of Cartagena (Spain) and Its Evaluation}

This section describes a use case application of the optimization model explained in the previous section, which served as a feasibility study for HADES. The study has two parts:

- Estimation of the maximum theoretical anchoring delay reduction attainable by terminal operators and its monetary value if the HADES system was used with the current port traffic.

- Estimation of the maximum theoretical additional traffic (and thus, income) that the Port of Cartagena could serve using the same infrastructure, without increasing the current service levels (i.e., anchoring congestion delays), thanks to using HADES.

\subsection{Dataset Description}

The results of this study are based on the data collected in the INTEGRA2 database for the 10 years between January 2011 and August 2020, describing the actual operations conducted in the port.

The study focuses on the berths of the E010 dock, at which 1000 calls occurred during the period noted. E010 is a multi-client dock used for loading/unloading liquid bulk that, in general, cannot be handled at other docks in the port. Therefore, the simultaneous arrival of ships on this front is an unavoidable cause of congestion in Cartagena since only one of them can use the berth, while the rest must wait.

From the initial 1000 calls, 960 are considered in the analysis because these calls do not involve other docks. The other 40 calls are assumed to be nonoptimizable, i.e., the vessel arrival times cannot be modified. Note that by restricting the view to one single dock, it is not allowing the simulated HADES allocation to exploit the distribution of vessels to different quays. This is because there are no historical records of the existing flexibility of arrivals during the last 10 years and, in general, such flexibility is infrequent in our use case. Therefore, only the benefits that arrival time optimization could bring about will be observed.

The E010 dock has an average occupation of 30\%, with an average call time of $45.28 \mathrm{~h}$, of which an average of $20 \mathrm{~h}$ is for anchoring and the rest $(25.26 \mathrm{~h})$ is actual E010 occupation. Of these $20 \mathrm{~h}$ of anchoring, an average of $6.3 \mathrm{~h}$ is caused by congestion, with an estimated cost of 500,000 dollarsR per year in ship freight. To determine congestion anchoring, it is assumed that a vessel delay was not caused by congestion anchoring provided that its anchoring started when the E010 dock was idle.

\subsection{Theoretical Anchoring Delay Reductions}

The first analysis estimates the improvements that could be obtained by a system that uses optimization techniques to assist and monitor a consensus among terminal operators in E010 to make small adjustments to vessel arrival dates. The target is to measure how much the original congestion anchoring $(6.3 \mathrm{~h})$ could have been reduced if the terminal operators had had a system like HADES to recommend adjustments.

The time margin flexibility considered is the same for all the vessels. Three tests are conducted, where each vessel can advance or delay its arrival, at the most, 6, 12, and $24 \mathrm{~h}$, from its recorded arrival time. These time margins are consistent with feasible operations according to terminal operators at HADES meetings. Moreover, it is assumed that the HADES system would have accurate information about future vessel arrivals, which inherently assumes fair and precise estimations and announcements by HADES users.

The results of the tests are shown in Table 3. The first row of the table refers to the average call time, subtracting the congestion time not caused by congestion ( $13.79 \mathrm{~h}$ on average), which is considered as nonoptimizable, i.e., we assume that HADES is not able to improve such time in any form, a conservative approach. Results show that congestion anchoring time can be reduced by $50 \%$ if the per-vessel time arrival flexibility $(\mathrm{H})$ is plus/minus $6 \mathrm{~h}$, by $75 \%$ for flexibility of $\mathrm{H}=12 \mathrm{~h}$, and it is practically eliminated with 
flexibility of one day. Assuming a freight charge of 20,000 dollars per day, these reductions would reach annual economic savings for the terminal clients of the E010 dock of between 220,000 dollars $(\mathrm{H}=6 \mathrm{~h})$ and 480,000 dollars $(\mathrm{H}=24 \mathrm{~h})$.

Table 3. Analysis results after application of HADES.

\begin{tabular}{lcccc}
\hline & Data_0 (h) & H= 6 (h) & \multicolumn{1}{c}{$\mathbf{H = 1 2}(\mathbf{h})$} & H $=\mathbf{2 4}$ (h) \\
\hline Average call time without noncongestion anchoring & 31.50 & 28.77 & 26.88 & 25.71 \\
\hline Average operation time & 25.26 & 25.26 & 25.26 & 25.26 \\
\hline Average congestion anchoring time & 6.23 & 3.50 & 1.62 & 0.44 \\
\hline Reduction of average congestion anchoring time & - & 2.73 & 4.61 & 5.79 \\
\hline Annual freight cost savings (1000s of dollars) & - & 227.5 & 384.3 & 482.2 \\
\hline
\end{tabular}

Average freight charge: 20,000 dollars/day.

\subsection{Theoretical Terminal Occupancy Decreases without Service Degradation}

A second study was carried out with the aim of estimating the increase in occupancy (and therefore income) that the Port of Cartagena could obtain from the E010 dock without increasing the average congestion anchoring delay above the current $6.3 \mathrm{~h}$.

In order to simulate the traffic that would arrive to dock E010 with loads higher or lower than those stored in the database, a scaling process of arrival times is used. Let us use $\mathrm{U}$ to denote the original average occupation of dock E010 during the observation period (January 2010 to August 2020), with $\mathrm{U} \approx 30 \%$. A realistic traffic arrival trace for a different average occupation $U^{\prime}$ is artificially created, which can then feed the same tests as the ones described in the previous section. The arrival date of the first vessel in the observation period is denoted as $t 0$. Then, giving a call $c, t(c)$ indicates the original relative arrival date of the vessel at port, measured as the time between its original date and $t 0$. In order to obtain a scaled version of traffic, the original relative arrival at time $t(c)$ is exchanged for another arrival at time $t(c) / x$, keeping the same duration of the operations at port. According to this process, a trace where the port is occupied at $60 \%$ (double occupation) would result in a trace where the arrivals are concentrated in 5 years, instead of the original 10 years of the dataset.

After scaling the traffic arrivals for different simulated occupations U for dock E010, the optimization procedure described in the previous section is applied to each of them, with time flexibilities $H$ of 6,12 , and $24 \mathrm{~h}$. The results are plotted in Figure 5 . The $x$-axis is the simulated occupation of E010, while the $y$-axis shows the normalized congestion delay observed. "Normalized" here means that the average anchoring delay is divided by the average occupation of E010 in each stay. Figure 5 clearly illustrates the benefits that the traffic smoothing effect produced by HADES could provide. In any case, average congestion delay increases in respect to dock occupation. This is a well-known effect of queue systems. The interesting aspect here is the quantification of how the arrival coordination controlled by HADES produces curves that are below the original service curve and are even better when greater flexibility is available. This means that service delays will be lower for the same dock occupation or that more vessels can be served (and thus increase port income) for the same target congestion delay. In this latter approach, the results indicate that exploiting the adjustments limited to 6,12 , or $24 \mathrm{~h}$ in the calls would allow them to double the occupation of front E010 (going from 30\% to levels of 55\% to $60 \%$ ), maintaining the same level of service (around $6 \mathrm{~h}$ of average congestion delay). 


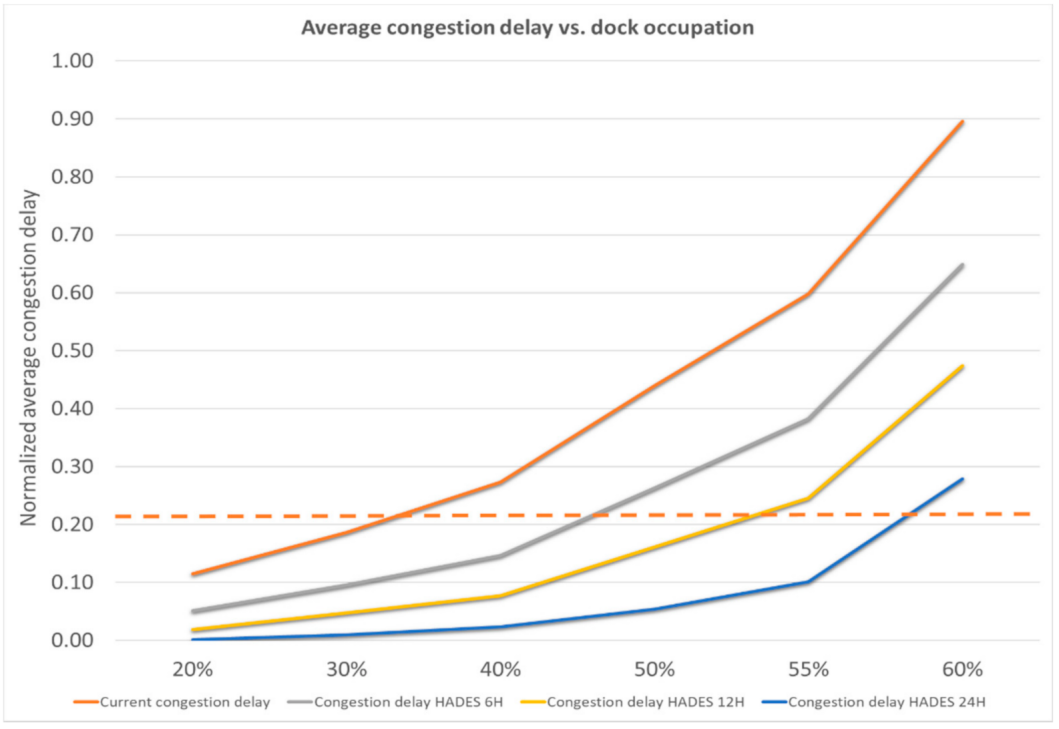

Figure 5. Estimated average congested delay at dock E010.

\section{Conclusions}

In this paper, the HADES system is presented. HADES is the first version of a web-based multi-client coordination system to be used by terminal operators, shipping agents, and port authorities that optimizes berth occupancy. The strategy of HADES is to incentivize voluntary time coordination among vessel arrivals to multi-client terminals in order to reduce congestion delays. This is of special interest in liquid bulk terminals, which often do not have the flexibility to allocate arriving vessels into more than one position and quay, in contrast to container-based terminals.

The paper describes the reasons for the creation of HADES, motivated by the needs of the Port of Cartagena (Spain) and, arguably, of other liquid bulk ports, and its main design guidelines. Then, the results of a feasibility study to assess the potential benefits of HADES and similar systems is presented when applied to a particular terminal (E010) in the Port of Cartagena. This study is based on an optimization model that is able to jointly optimize both quay allocation and vessel arrival time coordination. This is the main objective of HADES, but it is used in this study to assess the potential theoretical benefits that time coordination can bring by considering different realistic time flexibility windows $(6,12$, and $24 \mathrm{~h}$ ).

The results show that time coordination under the flexibility margins quoted as feasible by port terminals can bring significant benefits by reducing congestion delays of between $50 \%$ and $90 \%$. Alternatively, such coordination could be used to almost duplicate port occupation (from $30 \%$ to $55 \%$ ), providing the same level of service. These results show the good performance of HADES and validate interest in using temporal stay coordination as a means of reducing anchoring times caused by congestion. Therefore, the direct consequences are an increase in port profitability as ports can increase revenues by hosting a greater number of calls, maintaining the same infrastructure and the same level of service. Both issues have an impact on the economic benefit of the port, its activity, client loyalty, and the attraction of new clients, which will have an indirect impact on society.

The studies reported in this paper stimulate future research works based on the performance, user behavior, and feedback of the HADES proof-of-concept, which has been in place since July 2020, once enough data have been collected. For example, a complete system applied to the whole port will generate greater savings provided that more degrees of freedom are evaluated, such as interaction with more docks, dock flexibility with operations that can be performed on more than one dock, potential simultaneous occupation, and calls with several stays at different docks with possible flexibility in their order. The influence of changes in port loading/unloading rates due to pumping systems 
improvements or systems failures could also be considered in temporal coordination. Additionally, HADES is able to naturally accommodate the existence of different service level agreements among terminal operators and shipping companies; these agreements and other constraints result in different flexibilities time windows announced, an input to HADES optimization. In future work, artificial intelligence and machine learning could be tools to implement in the HADES platform to expand the multi-agent platform to other terminals and improve decision making.

Author Contributions: Conceptualization, P.J., J.M.G.-F., and P.P.-M.; methodology, P.J., J.M.G.-F., and P.P.-M.; software, P.P.-M.; validation, P.J., J.M.G.-F., and P.P.-M.; formal analysis, J.M.G.-F. and P.P.-M.; investigation, P.J., J.M.G.-F., and P.P.-M.; resources, J.M.G.-F.; data curation, P.P.-M.; writingoriginal draft preparation, P.J.; writing—review and editing, P.J., J.M.G.-F., and P.P.-M.; visualization, P.J., J.M.G.-F., and P.P.-M.; supervision, J.M.G.-F.; project administration, P.J.; funding acquisition, J.M.G.-F. All authors have read and agreed to the published version of the manuscript.

Funding: This research was funded by Port Authority of Cartagena, grant number 6071/19IMC.

Institutional Review Board Statement: Not applicable.

Informed Consent Statement: Not applicable.

Data Availability Statement: Not applicable.

Acknowledgments: The authors would like to thank Port Authority of Cartagena for data supplied, and terminal operators of docks E010 and E011 for their suggestions.

Conflicts of Interest: The authors declare no conflict of interest. The funders are represented by J.M.G.-F. in the whole process of the manuscript.

\section{References}

1. UNCTAD. Review of Maritime Transport 2019. Available online: https://unctad.org/webflyer/review-maritime-transport-2019 (accessed on 15 December 2020).

2. Meersman, H.; Van de Voorde, E.; Vanelslander, T. Port congestion and implications to maritime logistics. In Maritime Logistics; Emerald Group Publishing Limited: Bingley, UK, 2012; pp. 49-68. [CrossRef]

3. Suite Posidonia Operation Tool by Prodevelop. Available online: https://www.prodevelop.es/puertos/posidonia/posidoniaoperations (accessed on 15 December 2020).

4. Dropboard-Oil and Petrol (Chemical) by Systems Navigator. Available online: https:/ /www.systemsnavigator.com/schedulingfor-oil-petro-chemical?gclid=CjwKCAjwtNf6BRAwEiwAkt6UQqnKBpK1xX7gzG7xzsqgW8EGfc7ViuvfgVLb1KAlVGZ9 GeJwT17ZnxoC3sYQAvD_BwE (accessed on 15 December 2020).

5. Marine Enterprise Suite (MES) by Cirrus Logistics. Available online: https:/ / cirruslogistics.com/products / marine-enterprisesuite/marine-enterprise-suite/ (accessed on 15 December 2020).

6. de Langen, P.W.; van der Horst, M.R.; Konings, R. Cooperation and coordination in container barging. Marit. Transp. 2006, 3, 91-107.

7. Van Der Horst, M.R.; De Langen, P.W. Coordination in hinterland transport chains: A major challenge for the seaport community. Marit. Econ. Logist. 2008, 10, 108-129. [CrossRef]

8. Franc, P.; Van der Horst, M. Understanding hinterland service integration by shipping lines and terminal operators: A theoretical and empirical analysis. J. Transp. Geogr. 2010, 18, 557-566. [CrossRef]

9. Van den Berg, R.; De Langen, P.W. Hinterland strategies of port authorities: A case study of the port of Barcelona. Res. Transp. Econ. 2011, 33, 6-14. [CrossRef]

10. Van der Lugt, L.M.; Rodrigues, S.B.; Van den Berg, R. Co-evolution of the strategic reorientation of port actors: Insights from the Port of Rotterdam and the Port of Barcelona. J. Transp. Geogr. 2014, 41, 197-209. [CrossRef]

11. Van der Horst, M.; Kort, M.; Kuipers, B.; Geerlings, H. Coordination problems in container barging in the port of Rotterdam: An institutional analysis. Transp. Plan. Technol. 2019, 42, 187-199. [CrossRef]

12. PortChain-Denmark. Available online: https://www.portchain.com/ (accessed on 15 December 2020).

13. Port Authority of Valencia, Spain. Information Analysis to Detect Inefficiencies in Port Operations. Available online: https://www.valenciaport.com/valenciaport-se-convierte-en-el-puerto-mas-transparente-con-su-herramienta-deseguimiento-de-tiempos-de-escala / (accessed on 15 December 2020).

14. PortXchange-Rotterdam. Available online: https://www.portofrotterdam.com/en/port-forward/portxchange (accessed on 15 December 2020).

15. QronoPort-Antwerp. Available online: https:/ / qronoport.com. (accessed on 15 December 2020).

16. Wartsila-Finland. Available online: https://www.wartsila.com/marine (accessed on 15 December 2020). 
17. Bierwirth, C.; Meisel, F. A survey of berth allocation and quay crane scheduling problems in container terminals. Eur. J. Oper. Res. 2010, 202, 615-627. [CrossRef]

18. Imai, A.; Nishimura, E.; Papadimitriou, S. Berthing ships at a multi-user container terminal with a limited quay capacity. Transp. Res. Part E 2008, 44, 136-151. [CrossRef]

19. Zhou, P.-F.; Kang, H.-G. Study on berth and quay-crane allocation under stochastic environments in container terminal. Syst. Eng. Theory Pract. 2008, 28, 161-169. [CrossRef]

20. Han, X.-L.; Lu, Z.-Q.; Xi, L.-F. A proactive approach for simultaneous berth and quay crane scheduling problem with stochastic arrival and handling time. Eur. J. Oper. Res. 2010, 207, 1327-1340. [CrossRef]

21. Park, Y.M.; Kim, K.H. A scheduling method for berth and quay cranes. OR Spectr. 2003, 25, 1-23. [CrossRef]

22. Guan, Y.; Cheung, R.K. The berth allocation problem: Models and solution methods. OR Spectr. 2004, 26, 75-92. [CrossRef]

23. Gao, C.; Zhang, R.; Du, Y.; Chen, Q. A proactive and reactive framework for berth allocation with uncertainties. Presented at the Advanced Management Science (ICAMS), 2010 IEEE International Conference, Chengdu, China, 9-11 July 2010; Volume 3, pp. 144-149. [CrossRef]

24. Moorthy, R.; Teo, C.P. Berth management in container terminal: The template design problem. OR Spectr. 2006, 28, 495-518. [CrossRef]

25. Dai, J.; Lin, W.; Moorthy, R.; Teo, C.P. Berth allocation planning optimization in container terminals. In Supply Chain Analysis; Tang, C.S., Teo, C.P., Wei, K.K., Eds.; International Series in Operations Research, Management Science; Springer: Berlin/Heidelberg, Germany, 2008; Volume 119, pp. 69-104. [CrossRef]

26. Umang, N.; Bierlaire, M.; Vacca, I. Exact and heuristic methods to solve the berth allocation problem in bulk ports. Transp. Res. Part E Logist. Transp. Rev. 2013, 54, 14-31. [CrossRef]

27. Robenek, T.; Umang, N.; Bierlaire, M.; Ropke, S. A branch-and-price algorithm to solve the integrated berth allocation and yard assignment problem in bulk ports. Eur. J. Oper. Res. 2014, 235, 399-411. [CrossRef]

28. Lassoued, R.; Elloumi, A. The discrete and dynamic berth allocation problem in bulk port. In Proceedings of the 2019 6th International Conference on Control 2019, Decision and Information Technologies (CoDIT), Paris, France, 23-26 April 2019; pp. 1976-1980. [CrossRef]

29. Umang, N.; Bierlaire, M.; Erera, A.L. Real-time management of berth allocation with stochastic arrival and handling times. J. Sched. 2017, 20, 67-83. [CrossRef]

30. Pratap, S.; Nayak, A.; Cheikhrouhou, N.; Tiwari, M.K. Decision support system for discrete robust berth allocation. IFACPapersOnLine 2015, 48, 875-880. [CrossRef]

31. Pratap, S.; Nayak, A.; Kumar, A.; Cheikhrouhou, N.; Tiwari, M.K. An integrated decision support system for berth and ship unloader allocation in bulk material handling port. Comput. Ind. Eng. 2017, 106, 386-399. [CrossRef]

32. de León, A.D.; Lalla-Ruiz, E.; Melián-Batista, B.; Moreno-Vega, J.M. A Machine Learning-based system for berth scheduling at bulk terminals. Expert Syst. Appl. 2017, 87, 170-182. [CrossRef]

33. Port Authority of Cartagena. Memoria Anual 2019/Annual Report 2019. Cartagena. 2019. Available online: http://www.apc.es/ webapc/publicaciones/DOCUMENTACION (accessed on 15 December 2020).

34. Puertos del Estado. Pliego de Prescripciones Técnicas para la Contratación de Servicios para el Soporte y Mantenimiento de la Aplicación INTEGRA; Puertos del Estado: Madrid, Spain, 2014. 